\title{
Absence of PAX2 gene mutations in patients with primary familial vesicoureteric reflux
}

\author{
Kai-Luk Choi, Leslie A McNoe, Michelle C French, Parry J Guilford, Michael R Eccles
}

\begin{abstract}
Vesicoureteric reflux (VUR) is a common childhood condition characterised by regurgitation of urine from the bladder to the kidney. It is the commonest cause of end stage renal failure in children and an important cause in adults. Primary VUR is often familial, suggesting that genetic factors play an important role in its aetiology. Recently, VUR was observed as part of a syndrome, involving optic nerve colobomas and renal anomalies, caused by mutations of the PAX2 gene. PAX2 is a member of the paired box family of genes and is expressed in the ureteric bud and differentiating nephrogenic mesenchyme of the developing kidney. PAX2 has been shown to play a critical role in the development of both the kidney and the ureter. The occurrence of VUR in one family with the PAX2 mutation, and the expression pattern of PAX2 in developing ureteric bud, strongly suggested that PAX2 could be the cause of primary familial VUR. Single strand conformational polymorphism (SSCP) analysis of 23 affected subjects in eight families with primary familial VUR showed no alterations in exons 2-5 of the PAX2 gene. In addition, a polymorphic dinucleotide repeat marker located within the PAX2 gene segregated independently of the disease trait in one large family who primarily had VUR or reflux nephropathy. These results suggest that PAX2 is not a major cause of primary familial reflux.

$(\mathcal{F}$ Med Genet 1998;35:338-339)
\end{abstract}

Keywords: vesicoureteric reflux; reflux nephropathy; PAX2 gene

VUR is characterised by regurgitation of urine from the bladder to the kidney, ${ }^{1}$ and is found in up to $50 \%$ of infants and young children with a urinary tract infection. ${ }^{2}$ The kidney damage caused by VUR, termed reflux nephropathy, is responsible for approximately $25 \%$ of end stage renal failure in children. ${ }^{3}$ The congenital defect in VUR is an abnormality in the length, diameter, musculature, or innervation of the submucosal segment of ureter. ${ }^{4}$ The primary defect is thought to involve a developmental abnormality of the caudal portion of the ureteric bud. ${ }^{5}$ VUR is frequently clustered in families, ${ }^{6}$ and in most cases is not associated with any other anomalies (the occurrence of hereditary VUR in isolation is defined here as primary familial VUR), suggesting that genetic factors are involved in the cause of primary
VUR. Mutation in PAX2, a paired domain containing gene that is critical for urogenital development, ${ }^{78}$ is a good candidate for the aetiology of VUR. During development of the renal tract, PAX2 is expressed in the ureteric bud as well as in the developing kidney. Moreover, PAX2 gene mutations have recently been reported in a family with optic nerve colobomas, renal anomalies, and vesicoureteric reflux. ${ }^{9}$ Here we report mutation and linkage analysis of the PAX2 gene in nine families with VUR or reflux nephropathy or both to determine whether PAX2 mutations are associated with primary familial VUR. Despite the association of PAX 2 mutations in patients with renal-coloboma syndrome and VUR, our results suggest that PAX2 is not a major cause of familial reflux.

The patients analysed in this study were from eight families with either primary VUR or reflux nephropathy. VUR was determined by micturating cystourethrography, while reflux nephropathy was determined by renal function tests, ultrasound, or renal scan. The pedigrees of each of the families and the affected members of the families are shown in fig 1 .

Genomic DNA from 23 affected and 34 unaffected subjects from pedigrees A-H (fig 1) was analysed by single strand conformational polymorphism (SSCP) analysis of exons 2-5 of PAX2 as described previously. ${ }^{9}$ These exons include the paired box and octapeptide coding sequences, in which PAX2 mutations have previously been identified in patients with renalcoloboma syndrome. ${ }^{9-11}$ In our experience, this technique detects mutations in $60-70 \%$ of patients with renal-coloboma syndrome (M R Eccles, in preparation). No polymorphisms or mutations were detected in any of the families, who together represent up to eight distinct VUR alleles. While these findings are not conclusive, they suggest that exons 2-5 of PAX2 were not mutated in these subjects.

To exclude mutations in PAX2 as a cause of VUR, segregation of a highly polymorphic dinucleotide repeat marker within intron 8 of PAX $2^{12}$ was assessed in four families. Genomic DNA from 49 members of the four families was analysed by linkage analysis using the $\operatorname{PAX} 2(\mathrm{AC})_{\mathrm{n}}$ dinucleotide repeat and conditions as described previously. ${ }^{12}$ Many other chromosomal markers have been analysed in these families, providing strong evidence of the parentage of each child (data not shown). The allele patterns for the PAX2(AC) $)_{n}$ repeat are shown under the symbols in the respective pedigrees (fig 1). In the largest pedigree, the PAX2 alleles did not show evidence of cosegregation with VUR, but in the smaller pedigrees 

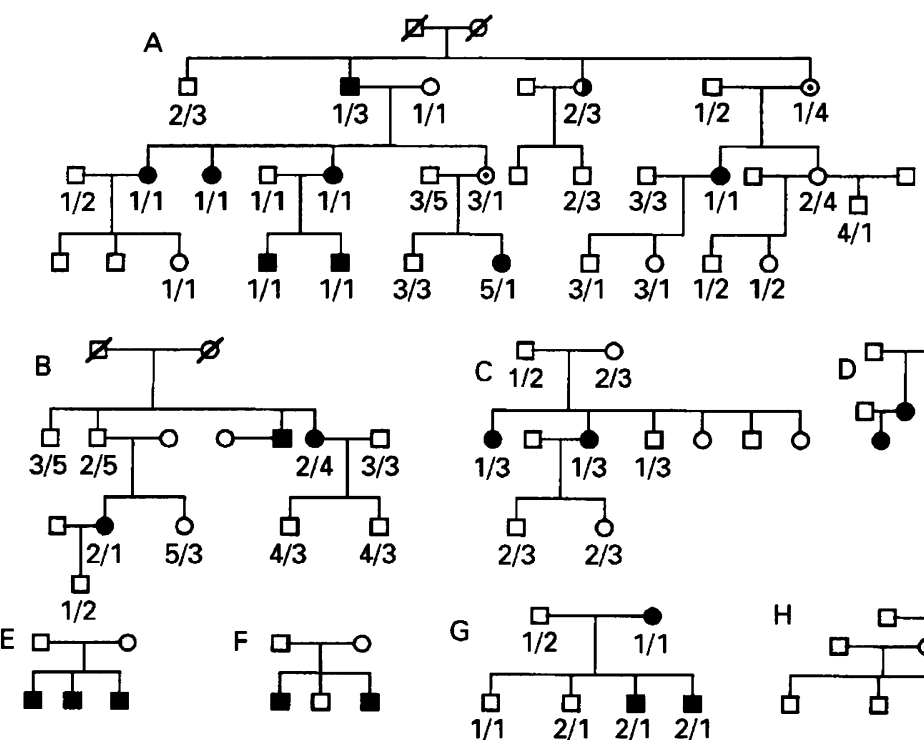

Figure 1 Pedigrees of eight families with VUR and reflux nephropathy, and genotype analysis of the PAX2 $(A C)_{n}$ repeat. Filled symbols represent affected subjects with VUR or reflux nephropathy or both. One subject in family $A$ had duplex ureter but no clinical evidence of VUR (half filled symbol). Several people in the pedigrees are obligate carriers (symbols with dots) and have affected sibs and affected offspring. The allelic pattern of the PAX2 $(A C)_{n}$ repeat is shown under each subject in whom DNA samples were analysed.

cosegregation could not be excluded. In one other large pedigree, it was also found that the PAX2(AC) $)_{n}$ repeat did not cosegregate with VUR (G Ehrlich, R Preston, F Schneck, personal communication). One subject in family A (half filled symbol) had a duplex ureter with no clinical evidence of VUR, although duplex collecting systems are frequently associated with VUR. ${ }^{13-16}$ Scoring the person with the duplex ureter in family $\mathrm{A}$ as affected, the penetrance of VUR was calculated to be $82 \%$. Using the MLINK computer program (LINKAGE 5.1 package) with a disease allele prevalence of $0.16 \%,{ }^{17}$ and assuming allele frequencies to be equal, the lod score of the PAX2 $(A C)_{n}$ repeat in family A was calculated to be $-3.6, \theta=0$. From this analysis the recombination distance that could be excluded was 4 $\mathrm{cM}$ either side of the PAX2(AC) ${ }_{n}$ marker.

In previous studies, PAX2 mutations have been identified in four patients with VUR, optic nerve coloboma, and renal disease ${ }^{9}$ (in preparation). In addition, seven other patients with renal-coloboma syndrome and PAX2 mutations have been described. ${ }^{10}{ }^{11}$ Despite the association of VUR with PAX2 mutations in a significant proportion of patients with renalcoloboma syndrome, and the observation that PAX2 is expressed in the developing ureteric tissue, we found no evidence for PAX2 mutations in patients with primary VUR in this study. This exclusion is not entirely definitive because only four of the 12 PAX2 exons were analysed by SSCP, although all mutations so far identified in PAX2 have been in these exons. ${ }^{91011}$ Cosegregation and linkage analysis of a dinucleotide repeat polymorphism within the PAX2 gene excluded PAX2 as a cause of VUR in the largest family available. These results suggest that PAX2 mutations are not likely to be a major cause of familial primary VUR. However, we have not discounted the possibility that PAX2 could be mutated in families with hereditary VUR and visual anomalies. The absence of PAX2 mutations in patients with primary VUR may assist in distinguishing VUR from renal-coloboma syndrome in which PAX2 mutations do occur.

We thank Dr M J Sullivan for discussions and Drs G Abbott and $R$ Bailey for DNA samples. This work was supported by grants from the Health Research Council of New Zealand, University of Otago Bequest, Lottery Health, and Cancer Society of New Zealand.

1 Bailey RR. An overview of reflux nephropathy. In: Hodson J, Kincaid-Smith P, eds. Reflux nephropathy. New York: Masson, 1979:3-13.

2 Report of the International Reflux Study Committee. Medical versus surgical treatment of primary vesicoureteral reflux. Pediatrics 1981;67:392-400.

3 Bailey RR, Lynn KI, Robson RA. End-stage reflux nephropathy. Renal Failure 1984;16:27-35.

4 Stephens FD, Lenaghan D. Anatomical basis and dynamics of vesicoureteral reflux. $\mathcal{f}$ Urol 1962;87:669-80.

5 Stephens FD. Correlation of ureteric orifice position with rephens FD. Correlation of ureteric orifice position with renal morphology. Trans Am Assoc Genitourin Surg 1976:53. ial and hereditary reflux nephropathy. In: Hodson J, Kincaid-Smith P, eds. Reflux nephropathy. New York: Masson, 1979:48-52.

7 Eccles MR, Wallis LJ, Fidler AE, Spurr NK, Goodfellow PJ, Reeve AE. Expression of the PAX2 gene in human fetal kidney and Wilms tumor. Cell Growth Differ 1992;3:27990 .

8 Strachan T, Read A. PAX genes. Curr Opin Genet Dev 1994; 4:427-38.

9 Sanyanusin P, Schimmenti LA, McNoe LA, et al. Mutation of the $P A X 2$ gene in a family with optic nerve colobomas, vesicoureteral reflux and renal anomalies. Nat Genet 1995; 9:358-63.

10 Schimmenti LA, Cunliffe HE, McNoe LA, et al. Further delineation of renal-coloboma syndrome in patients with delineation of renal-coloboma syndrome in patients with Am ₹ Hum Genet 1997;60:869-78.

11 Sanyanusin P, McNoe LA, Sullivan MJ, Weaver RG, Eccles MR. Mutation of $P A X 2$ in two siblings with renalcoloboma syndrome. Hum Mol Genet 1995;4:1717-20.

12 Sanyanusin P, Norrish JH, Ward TA, Nebel A, McNoe LA, Eccles MR. Genomic structure of the human PAX2 gene. Genomics 1996;35:258-61.

13 Whitaker J, Danks DM. A study of the inheritance of duplication of the kidneys and ureters. $\mathcal{F}$ Urol 1966;95:176-8.

14 Atwell JD, Cook PL, Strong L, Hyde I. The interrelationship between vesicoureteric reflux, trigonal abnormalities and a bifid pelvicalyceal system: a family study. $B r \mathcal{f} U$ rol 1977;49:97-105.

15 Atwell JD, Allen NH. The interrelationship between paraureteric diverticula, vesicoureteric reflux and duplication of ureteric diverticula, vesicoureteric reflux and duplication of the pelvicalyceal

16 Atwell JD. Familial pelviureteric junction hydronephrosis and its association with a duplex pelvicalyceal system and vesicoureteric reflux: a family study. $B r \mathcal{F}$ Urol $1985 ; 57: 365-$ 9.

17 Chapman CJ, Bailey RR, Janus ED, Abbott GD, Lynn KL. Vesicoureteric reflux: segregation analysis. Am $\mathcal{F}$ Med Genet 1985;20:577-84 